\title{
INVESTIGAR EN BIOÉTICA
}

Juan María Parent Jacquemin

La bioética es una ciencia ya bastante conocida. Se han publicado trabajos importantes en su seno y la necesidad de mayores conocimientos nos invita a abrir líneas de investigación y adentrarnos en los proyectos que surgen continuamente, por efecto del acelerado desarrollo de la biotecnología. Junto con este hecho, observamos que es urgente la revisión de la ética en general y, especialmente, en áreas donde el ser humano ocupa el primer lugar.

Los métodos de investigación en bioética son variados, de acuerdo con el punto de vista elegido por el investigador y por el medio académico en el que se desenvuelve. Nos centraremos aquí en un método aplicable sin dificultad en bioética.

La bioética es una rama de la ética. La ética es la ciencia del discernimiento del valor de lo bueno y lo malo de nuestras acciones; es una rama de la filosofía $\mathrm{y}$, consecuentemente, seguirá los pasos indicados en alguna de las numerosas ramas de la filosofía.

Elegiré como marco teórico el personalismo comunitario del filósofo francés Emmanuel Mounier. Un marco teórico es el conjunto de ideas que se han acumulado de manera estructurada en torno a determinadas acciones. No hay un solo marco teórico y es preciso, antes de iniciar la investigación, asegurarse de que se ha elegido conscientemente este marco. En otras palabras, el bioeticista no toma decisiones ni externaliza opiniones que sólo descansen en una tradición local, en las leyes escritas o en la intuición. Se requiere de un marco teórico también para separar los elementos que pertenecen de los que no pertenecen a nuestra área de estudio. Cerca de la bioética encontramos otras ciencias, como la antropología, la economía, las ciencias administrativas y muchas otras. Por esta razón, el marco teórico es esencial.

El segundo elemento que compone la investigación es el caso de estudio. En sí, el caso de estudio no es propiamente investigación científica porque es un caso aislado, un particular. El proceso que es necesario seguir, entonces, es comparar o enfrentar el caso de estudio ante el marco teórico.
Un caso frecuente de bioética es la negación de los Testigos de Jehová a recibir una transfusión de sangre. El gran número de personas que profesan esta fe da un carácter propio a la investigación, porque podríamos pensar que, dado que son muchos los afectados, dando una opinión sobre esta negativa estamos en la ciencia. Todavía no.

Si me sitúo en el personalismo comunitario, mis preguntas científicas dirigidas al caso serán: ¿es factible obtener, sin afectar la fe de los Testigos de Jehová, mediante leyes positivas, que abandonen esta práctica y así colaboren a su mayor personificación? ¿Seremos capaces, invirtiendo el objetivo, de convivir pacífica y creativamente con los Testigos entre nosotros? ¿Somos más personas cuando logramos entender y valorar la fe de los Testigos?

Al haber logrado esta reflexión ética, las respuestas obtenidas adquieren un carácter de universalidad, lo que en adelante permite resolver muchos conflictos morales.

La investigación en bioética aborda un problema concreto que debe ser atendido. Los sucesos concretos nos enseñan la gravedad de ciertos casos, la complejidad de otros que nos adiestran para pensar con más firmeza la teoría en la que se inserta el asunto tratado.

Notamos ahora la diferencia entre investigación científica y desarrollo tecnológico. Algunas veces debemos colocarnos en el ámbito de la tecnología y mejorar sus producciones. Con ello no hacemos avanzar el conocimiento. La investigación científica, por su parte, nos conduce a soluciones universales.

Observemos la diferencia entre resolver hoy y aquí un caso de no-transfusión violando, por ejemplo, la sensibilidad del Testigo al aplicar la Constitución. Es una solución mala, pero nos libera de pensar. Otra cosa es conseguir toda la documentación existente (libros, artículos de revistas, películas y otros), quedarse con lo valioso y crear a partir de este estudio una solución o varias soluciones aplica- 
bles a todos los Testigos de Jehová en todas partes del mundo: cosa difícil pero posible.

El resultado obtenido alcanza otra dimensión si al enfrentar caso y teoría estamos convencidos de que ésta debe revisada y entramos así en la sociedad científica donde se escuchará el descubrimiento importante que se aporta al conocimiento universal.

Añadamos que este segundo resultado es muy difícil de alcanzar. Se requiere un profundo conocimiento de la teoría y una muy amplia observación de los casos que se presentan permanentemente.

Pero no hemos terminado. La ciencia se compone ciertamente de una teoría, pero no se detiene ahí. En esta esfera superior contamos también con las leyes científicas, las hipótesis y los axiomas. En cada uno de estos peldaños del saber podemos aportar algo gracias al caso de estudio que hemos tomado como ejemplo. A un nivel más bajo tenemos la metodología y los métodos que deben ser revisados $\mathrm{y}$, eventualmente, modificados.

Por ejemplo, la cirugía sigue siendo una práctica cotidiana en los hospitales y no exenta de riesgos. El bioeticista sabrá medirlos y crear una nueva metodología quirúrgica que los reduzca aún más, porque el enfermo es una persona que merece toda nuestra atención. La persona será más ella misma si la cirugía que se le aplica es más exitosa; la comunidad familiar o grupal lo será más si uno de sus miembros recupera la salud, sin haber corrido tantos riesgos.

La investigación en bioética es a la vez documental y empírica. Documental, en cuanto el investigador profundiza su marco teórico con lecturas, conferencias, debates, mesas redondas y otros; empírica porque el investigador observa el medio en el que su intervención será necesaria.

La investigación en bioética es comunitaria (no individual). Los variados puntos de vista de científicos de diversas disciplinas se conjugan y se oponen en el necesario debate que se establece entre los responsables de emitir un veredicto ético. A través de la práctica y la asesoría externa, deberá aprenderse a relacionar puntos de vista opuestos y lograr el consenso. La interdisciplinariedad demanda largo entrenamiento para captar el lenguaje del otro y comunicar.

Estas cortas reflexiones nos abren la puerta hacia las técnicas de investigación propias de la filosofía, la ética y la bioética. 